Vol 41 (2016) No 184 75-89

\title{
The Game Plan: Four Contradictions in the Development of World Class Universities from the Global South
}

\author{
Yisu Zhou ${ }^{1}$, Jinting $\mathrm{Wu}^{2}$
}

\begin{abstract}
Globalization in the 21st century provides fresh opportunities for new institutions to establish themselves. Through globalization, academic professionals, technological advancements, and capital can move across borders on a grand scale with greater ease. Many emerging societies have capitalized on this rapid economic development to build world-class, comprehensive research universities. Incidentally, these research universities often involve competing goals, such as the demand for practical labor market training, the need to incorporate the German research-university model, the desire for a liberal arts education, and the call for cultivating global-minded citizenship. With these goals posing distinctive demands, higher education institutions are often laden with tensions and contradictions. This paper conceptualizes the developmental process of higher education institutions by juxtaposing four sets of inter-related contradictions: research versus teaching; looking outward versus inward; quantity versus quality; and egalitarianism versus hierarchy. Such contradictions are examined in the context of higher education institution's developmental priority to achieve world-class status. Our analysis raises questions about the long-term sustainability of such a strategy. Although the issues identified in this paper are prevalent in the global south, i.e. universities at the periphery of knowledge production vis-a-vis those in North America and Europe, we believe they are common themes with repercussions for institutions elsewhere.
\end{abstract}

Keywords

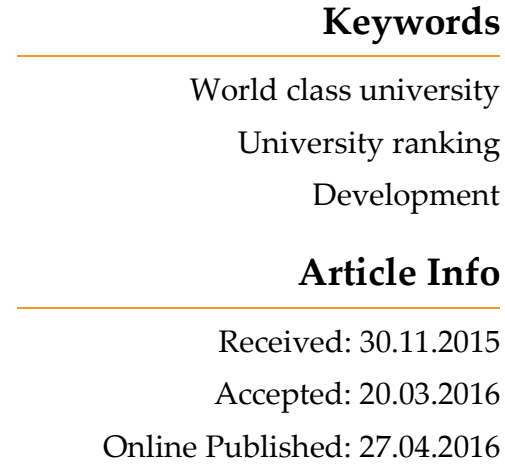

DOI: $10.15390 /$ EB.2016.6152

\section{Introduction}

John Meyer and colleagues, in a 2008 contribution, made an overwhelmingly positive statement that describes higher education as the central cultural institution of modern society (Meyer, Ramirez, Frank, \& Schofer, 2008). One way to interpret such optimism is that, as David Baker (2014) notes, higher education has profoundly shaped the culture of education and produced the "schooled society" on a worldwide scale. Baker argues, "the longevity of the university in a world where so many other institutional forms have died out attests to the staying power of its original function" (Baker, 2014, p. 63). The global diffusion and massification of higher education today continues to

${ }^{1}$ University of Macau, Faculty of Education, Macao, zhouyisu@umac.mo

2 University of Macau, Faculty of Education, Macao, wujinting@umac.mo 
attest to the university as a unique institution with deep sociological impacts on knowledge production, the dynamics of learning and teaching, and societal transformation. These primary elements of higher education correspond to the three roles of the universities in research, teaching, and social services. From the vantage point of the Global South ${ }^{1}$ in particular, higher education is at the heart of social change through which nations of various socioeconomic statuses appropriate a common global culture of the schooled society. Building a research-intensified university not only becomes a key driving force to the growth of economy, but also reflects the dynamic interactions among different parts of the world. The observers of higher education have identified a trend in the rise of the "super research university," a model initially developed in the United States that is now increasingly being adopted by most nations throughout the world (Mohrman, Wanhua, \& Baker, 2008; Cole, 2009).

Despite the all too familiar litany of critiques leveled at modern universities, such as the ever increasing commercialization, neo-liberal political perspectives, and the diminishing institutional mission to serve the public good, the pursuit of excellence in higher education in the global south has often been largely equated with obtaining global recognition. In part, what counts as quality is often assessed through global ranking league tables produced by major ranking systems including the U.S News \& World Report in the USA, the Times Higher Education supplement in the UK, and the Shanghai Jiaotong University Academic Ranking in China. The global educational culture at-large marks a new era of knowledge production, which drives more universities to be research-intensive, promotes the scientization of disciplines, and leads to worldwide competition for faculty, students, and funding (Baker, 2014).

What is noteworthy is the rise of science and technology as the dominant framework against which traditional disciplines outside the sciences (such as the arts and humanities) are increasingly pressured to adopt in regards to the same model of scholarship and productivity (see Bosco, 2012 for an example in a public university in Hong Kong; see also Stromquist, 2012, p. 167-9). Another controversial aspect of the super research university is the changing mode of intellectual inquiry. The traditional independent pattern of inquiry is overshadowed by a multinational collaboration involving research teams, graduate students, and funding streams across the physical and disciplinary borders, and is implemented under an entrepreneurial orientation emphasizing the applied value and marketability of scholarship. Marginson and Considine (2000), for instance, argue that such enterprise universities seek to maintain their advantage by using universalized, market-oriented models. As a result, the expectation for the faculty has also shifted to multiple and often conflicting agendas, including producing publishable results, teaching and advising students, obtaining competitive research funding, providing services to the university and the community, and working as international marketers (Schapper \& Mayson, 2005, p. 185). Additionally, academics' professional lives are increasingly internationalized, whether of their choice or not, as they are required to publish in English-language journals (in an effort to be globally accessible), increase their visibility in the global chain of knowledge production, and contribute to their institution's global ranking.

\footnotetext{
${ }^{1}$ We are cognizant of the controversies in naming parts of the world as Third World, Developing World, Low and MiddleIncome World, and more recently, Global South. While these names are often associated with a country's or a region's underdeveloped or developing economy, they also tend to reinforce the stereotypes and hierarchy between countries, even their colonizer-colonized relationship as argued by Shose Kessi, a social psychologist at the University of Cape Town (Silver, 2015). The relatively new term 'Majority World' is used as a reminder that the West is but a very small minority on the globe. While there is no space in our article to fully elaborate the naming debate, we acknowledge there is no objective way to classify the world and each label has its own limitations. In this article, we adopt the imperfect term 'Global South' not as a geographic label, but as a broad socio-economic and political divide of countries into centers and peripheries which is then mapped onto forms of knowledge production we see in higher education globalization today.
} 
Described as a stunning educational development, the super research university is often talked about interchangeably with the "world-class university" (WCU), with the priority on research rapidly becoming the accepted standard to judge the prestige of a higher education institution. However, what counts as "quality" or "world-class" in higher education is difficult to capture, and is to some extent, contextually dependent and culturally specific. After all, higher education institutions (HEIs) are not only, and not always global in orientation, but have to serve local social needs which are diverse according to different stakeholders. But in reality, on the road to becoming a WCU, these goals weigh differently for HEI administrators in the global south.

Higher education development in the global south remains to a large extent tethered to the institutional model spearheaded in the West, reinforcing the intellectual dominance of Euro-America and the subordination of peripheral countries. In this paper, we do not intend to systematically assess the relative benefits and costs of building research-intense world-class universities in the global south. Rather, we conceive it as an educational reform movement where the rule of the game (i.e. obtaining world-class status) has unintended consequences not only for HEIs but also for the academic profession. We aim to explore four sets of contradictions intertwined with the building of world-class universities in the global south. Although HEIs are likely in their golden era, as there are as many as 16,000 universities in the world and the number of people who now have access to higher education is at a historical high, such contradictions can be seen within many aspiring HEIs in emerging places.

As Ball (2003) rightly argues, a key aspect of the current educational reform movement is the establishment of a new form of control of the field of judgment, i.e., who is to determine what counts as valuable performance, what is effective knowledge production, what indicators are considered valid, and what it means to be an academic. Internationalization regulates actors both inside and outside the academy: rather than carving out a space of individual autonomy, it regulates complex social processes and events into misleadingly objective categories of judgment. This new field of judgment, shaped by academic community, established HEIs, influential academics, and entrepreneurs, inserts itself over emerging HEIs.

As American universities topped various global rankings, the American model is championed around the globe. Specifically, the American model is revered on the global stage for the way American HEIs are run, their organizational structure, and its educational practices. As Carey (2015) observes, this particular model of higher education is a hybrid of three different traditions. The first of which is the institutions' close ties with the economy. Unlike medieval universities, which largely distance themselves from the development of practical skills and knowledge, American universities put the training of skilled people at the very top of its mission. Land grant institutions are examples of this type of pedagogy. The second tradition is the German research university model. Though it was Germany that first developed the university model which gave much freedom to the independent lecturer to advance knowledge, this mode of scholarship became popular after John Hopkins introduced this very principle to the United States in 1876. Instead of training professionals, this model put research and related instruction at its core. The universities were consequently organized around autonomous divisions based on research disciplines. The third tradition is liberal arts education. Liberal arts advocates, such as John Newman, believed higher education's mission lies at

raising the intellectual tone of the society, at cultivating the public mind, at purifying the national taste, at supplying true principles to popular enthusiasm and fixed aims to popular aspiration, at giving enlargement and sobriety to the ideas of the age, at facilitating the exercise of political power, and refining the intercourse of private life" (Newman, 1893, p. 177-178).

To achieve these purposes, the liberal arts education focuses on the teaching and reading of classics and the canon. The university's mission therefore is to cultivate a whole person. 
As the American higher education history shows, these three goals--practical training, research, and liberal arts education--are not always compatible with each other. Instead of idealizing the American model, Carey (2015) shows that to house three distinctive goals under one institution creates tensions within universities as they demand different plans for development and compete for resources. Theses tensions would undermine long-term stability of the institution. But as the United States became the largest economy in the world, and American universities consistently top global rankings, policy borrowers elsewhere seem to neglect the internal contradictions of the American model and openly accept the American university as the ideal. Moreover, emerging institutions wish to tweak this model in order to achieve global recognition in a very short time frame.

Our observations leads us to the belief that such institutional isomorphism magnifies internal contradictions within this model as the social and cultural grounds can be vastly different in the host nation/region. Furthermore, these tensions are catalyzed by a compressed developmental time frame that aims to get things done as soon as possible. This paper is an attempt to theorize the development of HEIs in emerging economies under the framework of four sets of contradictions. By conducting this analysis, our goal is to reaffirm that solutions to these contradictions are essential to long term sustainability for emerging institutions.

\section{The Four Sets of Contradictions}

\section{Research vs. Teaching}

For HEIs who wanted to carve a global identity, research activities and outcomes have become an essential component that no university can afford to ignore. Observers (Stromquist, 2012; Bosco, 2012; Chen, 2015) all seem to point out that prestigious institutions place great emphasis on research, and current global ranking metrics weigh heavily toward research output. For instance, the Carnegie Foundation for the Advancement of Teaching classifies HEIs in the United States into three categories, including research universities very high research activity (RU/VH), research universities high research activity $(\mathrm{RU} / \mathrm{H})$, and doctoral/research universities (RU). These categories are made on the basis of the degree level a HEI offers and the amount of research produced. In addition, Association of American Universities (AAU) also selects sixty-plus research-intensive universities as leading exemplars of institutional excellence. The structure of this knowledge hierarchy incentivizes newcomers to prioritize research activities first and foremost, by consciously redistributing internal resources, including monetary and workload, between academic units and faculty members. Units that can generate a higher level of outputs in terms of academic articles, patents, and industrial products are given priority for development, whilst those who focus more on teaching are sidelined.

This shift in university priority is more than a scheme that purposely devalues teaching, we would argue, with roots dating back to two distinctive sources. From one end, teaching activity involves a different kind of risk and uncertainty compared to research activities. As David Cohen (1988) rightfully put, "Teaching is a practice of human improvement. It promises students intellectual growth, social learning, better jobs, and civilized sensibilities" (Cohen, 1988, p. 55). Teaching, Cohen argues, is inherently problematic since it directly puts the teacher in a situation where they have to find practical solutions to difficult questions in modern life such as: "[T]he meaning of progress, the means of achieving it, and the difficulties of knowing what we have done, how well, and how we did it, among others" (Cohen, 1988, p. 56) As an institution, modern day universities promise its students personal betterment, but, as Cohen $(1988$, p. 56) asserts, "the nature of these improvements is uncertain." For anyone who works with students on a daily bases, it will be easy to see that the teaching process is unpredictable and mysterious whilst generating complex and ambiguous results. Such challenges are faced by students as well. To make a commitment to learning means that students have to admit that their present achievement is not enough. The fear of failure does not only come 
from the day they take an assessment and are told that they have yet to master the skills and ideas they wish to learn, but also the painful realization that they have not become the person they thought they would.

These uncertainties in teaching and learning, argues Cohen $(1988,2011)$, are not solvable on a personal level. The approach that many successful institutions have taken to reducing the risks involved in instruction is to build an institution-level basis of understanding so that individual instructors can benefit from a collective knowledge, and can have access to best-practices for teaching and learning. Yet to build such institutional basis of knowledge requires HEIs to prioritize teaching and learning and to set up arrangements that bring individual instructors together to share experience and collaborate on teaching activities. Without these institutional arrangements in place, individual instructors could easily choose to reduce the difficulties of teaching by defining knowledge in more linear, clearer ways. It is no wonder that to come up with meaningful guidelines and clear incentives on teaching, other than simply using student surveys to evaluate teaching effectiveness, is very difficult. This requires much ground work and internal expertise to be developed. On the other hand, without emphasis on teaching, the teaching faculty typically feels marginalized compared to the research-oriented faculty members. Inside the HEIs, teaching and research thus requires different evaluative standards and support structures. The competition between the two always existed, but as research outputs are prized at a higher premium, the commitment to improving teaching becomes more and more difficult.

This leads to the second source of the issue. The assessment of research can be done on a much smaller scale (at the very least, students do not need to be involved). Research portfolios can be quantified and compared across faculties and disciplines (though such practice is not without problems, we leave this discussion to the third contradiction). Comparatively, when institutions wish to quantify the quality of teaching, it is often problematic. For institutions who wish to climb up various university league tables, it is key to align the research and teaching evaluation with external criterion, which can be problematic. Take the Times Higher Education (THE) World University Ranking as an example ${ }^{2}$. It lists that teaching is worth $30 \%$ of the total ranking score. This category is measured using the following criteria:

1. A reputation survey by other institutions (15\%)

2. Staff-to-student ratio (4.5\%)

3. Ratio of doctoral to bachelor's degree awarded (2.25\%)

4. Number of doctorates awarded by an institution, scaled against the size of the academic staff $(6 \%)$

5. Institutional income scaled against academic staff numbers (2.25\%)

\footnotetext{
${ }^{2}$ We are not vouching for the current university ranking system by using this example. We simply wish to make the point that university rankings all put disproportionate emphasis on research component. For discussion about the validity and reliability of university ranking, see Dill and Soo (2005) and Shin and Toutkoushian (2011).
} 
These criteria only remotely correlate with teaching quality. Therefore, university administrators whose top priority is to improve their ranking have little incentive to spend time and resources to improve faculty teaching. Other ranking criteria use slightly different measures, but are more or less the same. If we look at the research assessment of THE's rubric, which actually weighs $60 \%$ of the final score:

1) Research: volume, income, reputation (30\%)

a) A reputation survey by other institutions (18\%)

b) University research income (6\%)

c) Research output (academic papers) scaled against staff members (6\%).

2) Citations: Research influence. Number of times a university's published work is cited $(30 \%)$

Despite the ambiguity in the reputation survey, arguably these indicators correlate with research capacity at a higher degree. Most importantly, they are easily quantifiable and are thus appealing to university administration. The combination of these external and internal conditions is such that research activity becomes a top priority in emerging HEIs. Teaching is largely considered a domestic issue that has little international relevance. Despite an ongoing discussion about faculty professional development to promote effective pedagogies, there is no clear playbook at the international level on how to improve teaching, and the individual institution is left to decide on bestpractices, which often leads to discordant and unhelpful initiatives. While there are influential international standards on research, similar standards on teaching are largely absent. The technology that's required to enhance teaching, the institutional fabric that supports teaching activities, and the effort to help faculty members who struggle with teaching are largely missing from the overall picture.

\section{Looking Outward vs. Inward}

Despite ambiguity in the term "world class universities" (Rhoads, Wang, Shi, \& Yongcai, 2014), one thing is clear: the pursuit of excellence in education has often times been equated with obtaining global recognition. One way to differentiate between these two seemingly identical goals (the pursuit of excellence and the obtaining of global recognition) is to ask the question: to whom do HEIs serve? HEIs, as a form of education institution, serve different constituencies. As in the American case, the local economy could demand a workforce equipped with particular skills, while the research community could be focusing on the needs of the future as they conduct research that has very little practical relevance. But the global ranking system introduced something new by posing new rules and goals from the outside. And by actively engaging in the process of status attainment, emerging HEIs have increasingly turned outward in order to raise their prestige, rather than searching inward; for there is little reward of doing so on a global stage. Instead of creating a "new game" by setting its own rules and standards based on the needs of the local constituency, it is natural for emerging HEIs to dwell in the familiar global landscape of higher education development. This shift of focus has two implications. First, a movement towards global recognition often means adopting an existing hierarchical power structure rather than breaking away from the hegemony of the Western or Eurocentric practices. Secondly, the university could alienate itself from the local community. After all, garnering global ranking while satisfying local demand can be very loosely coupled, if not totally mutually exclusive.

The process of looking outward usually manifests itself in adopting international standards or making alliances with established organizations. No doubt such practice has its merits in improving the quality of teaching and research, but it gives a particular signal to internal members of the universities. A useful concept for us to understand the implications in looking out is the distinction 
between "use value" and "exchange value" in the education world (Labaree, 1997a; 1997b). Education programs have use value if its constituency believes the content it offers to be intrinsically useful. For instance, a teacher training program to develop local teachers, or a talented math program that nourishes aspiring high school students. The use value aspect requires education to "provide students with a useful array of competencies that are required for constructive citizenship in a democratic society or for productive work in a market society" (Labaree, 1997a, p. 54-55). Yet these activities have low exchange value on a global stage. It is difficult to quantify the impact of such activities to begin with, consequently making a comparison across HEIs problematic, which is a core feature of global ranking systems. The determinants of exchange values rely on a multitude of elements: prestige, recognition, awards, etc. To increase the exchange value, HEIs must create commodities (i.e. knowledge, patent, product, etc.) that can be accepted and examined in other countries/regions.

Since use value is difficult to quantify and exchange value carries more weight in the status attainment process, there is very little doubt that any shrewd administrators would put more emphasis on the latter. Many university presidents are tasked by government officials with the goal of achieving the WCU status. Without democratic control, it is difficult to imagine how HEIs will not lean toward creating more exchange values, and excuse themselves from creating use values for local constituencies. Emerging HEIs typically design their development strategy with a sense of urgency. Typically benefitting from a booming economy, emerging HEIs are better positioned resource-wise from state investment but fluctuation of the world economy in today's environment means a high uncertainty of sustained support from the national government or outside donors. Thus, many emerging HEIs have a limited time window for success. Their developmental trajectory is typically projected in a period of ten to twenty years. In order to achieve world class status in this relatively compressed framework, compromises must be made. Under this line of thinking, looking outward trumps looking inward and democratic accountability is over looked.

What is the consequence then, of favoring the outward-looking mindset? On the operational level, programs with little international relevance, such as teacher training, social work, nursing, etc., will not get enough support for development. To be sure, the advancement and growth of high quality programs requires intensive coordination with the local community. But with such a low exchange value, university presidents have little enthusiasm to invest in the development of these programs or reward faculties who excel in such tasks. One notices that similar contradiction exists in the promotion and evaluation of clinical faculty versus research faculty, especially in professional schools such as medicine, law, and education. Decisions from the top have profound implications at the ground level, as the allocation of various types of resources and the design of the curriculum all follow a university's inward or outward direction.

The tension between looking outward and inward is hardly new, as it reflects the pressure to serve the local community and contribute to national development on the one hand, all the while participating in a world system for global legitimacy on the other (Altbach, 1998; Knight \& De Wit, 1997). On an epistemological level, the binary logic of universal-parochial, international-local echoes the observation of many scholars about the unequal field of social science knowledge production (Connell, 2007; Chen, 2010; Takayama, 2014). The pursuit of scholarship has always been enmeshed in geopolitical struggles and the difficult balancing of the national and local interests with international orientations. A particular Eurocentric context of modernity has been upheld as the transcendent norm through which to explain the "rest" of the world, which has been characterized as a "deficient" latecomer on the linear stagiest developmental axis. The production of academic knowledge, therefore, is largely calibrated by and through the Eurocentric hegemony as a continuing legacy of colonialism. The discourse of "the West and the Rest" shapes not only Western scholarship of the 
"others," but also powerfully intersects with hegemony within the global south in subtle yet ubiquitous forms. As the Chinese scholar Sun Ge (2000) argues, the dominance of Western universalism in knowledge production in Asia is underpinned by a deep sense of ambivalence where the West is both an object of desire and resentment, both a source of critique and emulation, an ultimate other against which one's own sense of self is measured.

In his well-acclaimed book Asia as Method (2010), Chen Kuan-Hsing proposes shifting our points of references from the West to Asia (and the global south) in order to transform the existing mode of knowledge production in the global south. Chen considers such proposals as a self-reflexive movement to build a broad regional system of references, to grant Asia unique analytical value with its rich multiplicity and heterogeneity, and to break away from the old East-West binary. As we've tried to show in this paper, HEIs in the global south often look at the Euro-American West as a measure of success, a goal to reach, and an object of emulation. This model of "West as method" has dominated the discourse and knowledge produced at the institutional site of the university for quite some time (Chen, 2010). An alternative paradigm, to borrow Chen's insight, is to treat the EuroAmerican West as one cultural source among many others, which has become an integral part of, but never fully envelops, the formation of local practices. Perhaps what is needed is a comparison of pluralist practices and modes of knowledge production within the Global South. Not doing so might lead to what sociologist Robert Merton (1968) describes as the Mathew Effect in which the advantage of economic (and in our case, cultural and epistemological) capital becomes cumulative and reproduced over time in the unequal global playing field. The process of inter-referencing avoids the mistake of using the West as the singular world standard and allows for a new vision of higher education development that is critical and self-reflexive, that goes beyond the binary of looking outward or inward, and that embraces in-between spaces of rich dialogic possibilities.

\section{Quality vs. Quantity}

As we show in the Research vs. Teaching section, a university's ranking status is heavily impacted by its research profile. Yet in this conundrum, producing high impact research has a very ambiguous meaning. On one hand, using a singular metric to evaluate all research output across departments does help HEI administrations to benchmark themselves against one another. It provides a predictable path for HEI administrators to amass a substantial amount of research output in the developmental time frame. It also helps to establish a baseline for ensuring the quality of research to some extent. On the other hand, the ironic twist of the "impact versus impact factor" indicates the arbitrary nature of the academic audit culture that often puts closures on, rather than opening up, knowledge production and cross-cultural fertilization. While Western journals are assumed to have universal application, local cases are conceived of as having limited interests, and therefore only secondary or derivative. Science disciplines that tend to publish short papers in English journals are the least affected by the assessment exercise, as English is upheld as the Lingua Franca in knowledge production. Researchers in the social sciences and humanities who can engage in the "scientification" of knowledge production also benefit mostly from this repositioning of institutional focus. These researchers who can organize research teams often equates productivity in production to the division of labors. On the other side of the knowledge production spectrum, scholars in the humanities and some social sciences whose works require lengthy fieldwork or archival research, and those who write book-length manuscripts and edited volumes (without citation indexes) are primarily disadvantaged in the arms race of "publish or perish." 
The push for WCU status has heightened the expectation for faster academic outputs and deliverables, which may lead faculty members to compromise and use shortcuts in order to survive in the competitive environment. The university promotion system that rewards individuals who engage successfully with its norms enables an environment that produces calculating professionals, dampens the quality of peer relations, and diminishes the central principles of caring and nurturing in higher education in service of the good of humanity and public interests. In such a numerically construed mode of evaluating excellence, as Lynch (2015) observes, "[t]here is little incentive to invest personal time with students, to be a public intellectual and/or to investigate the vested interests behind one's own research funding" (p. 201).

In all academic disciplines, the system pushes the individual researcher to be more calculating. The pragmatic strategy many adopted is to encourage faculty members to publish in "internationally competitive journals," no matter what the term constitutes. Once again, the distinction between use value and exchange value is a useful concept for understanding the situation. Traditionally, in certain areas such as the sciences, the knowledge production cycle is arguably to some extent divorced from the actual demand in social and economic life. Yet, once one dives into areas of social sciences and humanities, the quality of work (research and teaching included) is inevitably jointly determined by the profession and local community. In the pursuit of WCU, however, the vetting of the quality of research work is largely relinquished to the external professional community, most of which are overseas and do not necessarily understand the local demand of knowledge. Again, while the dynamics between global academia and local demand always exist, the current development model that yields the trust of making judgments on quality to the outsider therefore leaves no incentive for faculty members to conduct research that has local relevance.

In addition, while the definition of quality remains ambiguous, the idea of quantity is straightforward. Emerging HEIs meticulously counted the number of research outputs because these figures put them on the map with other established institutions. As a result, researchers take cues to be risk-averse and to engage in a predictable path of research. The critical stance of offering a social analysis of society, even if contradicting mainstream ideologies and values, is historically a defining quality of world class universities. Intellectual freedom and the critical institutional culture, as Rhoads and Szelényi argue, are the responsibility and social conscience of modern universities (2011). However, the elevation of research productivity and world ranking may at times work against other equally important higher education missions, such as teaching, mentoring, and service to the public good. 


\section{Egalitarianism vs. Hierarchy}

Comparative scholars have argued that the notion of academic autonomy, largely derived from the European intellectual tradition of liberalism, is not universally fitting for all cultural contexts in the conceptualization of the WCU (Hayhoe, 2001; Li, 2012). In some settings, hierarchy may be favored over autonomy to achieve significant results in a compressed timeframe. At the institutional level, for instance, the Chinese state plays a significant role in formulating policies, providing priority funding, and explicitly leading the efforts to create WCUs in the nation, which is evidenced by two prominent projects $21 / 1$ and $98 / 5$ aimed to promote elite universities with world standards. ${ }^{3}$ Like China, in 2014, Japan selected 37 key institutions as the Super Global Universities who will receive special funding from the Ministry of Education for up to 10 years (Rappleye \& Vickers, 2015). This latest government-led efforts attempt to revitalize and internationalize Japanese universities. The similar "state instrumentalist" approach features top-down bureaucratic intervention and generates quick centralized effects, yet also exhibits strong tendencies toward conformity and hierarchy, giving individual universities and academic staff very little room for self-governance. This development model targets accelerated research performance in a limited timeframe, often at the expense of social equity, inclusiveness, and egalitarianism in the long-run. Who gets the state money, and who competes successfully in the field of status is often not a transparent matter but based on institutional legacies and state priorities. It results in the enduring hierarchy where institutions and academic staff are evaluated according to one set of criteria, i.e. research outputs, for access to resources and status (Zha, 2009). Such a top-down state-directed process may reproduce the ideology of elitism, dilute independent scholarly reflexivity, and undermine equal opportunities for students enrolled in different universities; yet ironically it also serves as a pragmatic tool for policymakers to achieve tangible results and move up the ranking league tables fairly quickly.

Within each institution, a hierarchy is also maintained to justify the priority of research over teaching. Such a hierarchy is devised on two levels. First, there is a distinction between newly recruited faculty under a "research regime," and legacy employees who have joined the institution prior to the reform. While the new recruits are typically put under some sort of "publish or perish" regimes which prioritize research over teaching, the situation for legacy employees are more delicate. Some of the faculty who are seen as having the potential to produce research work are given similar terms. But in the majority of cases, their skill repertoire does not permit them to participate in the new game. Thus, some are being assigned to the "teaching regime" with a heavy teaching duty and student advising roles in an effort to balance the student-to-faculty ratio.

On another level, as discussed in the previous section, the research role is often prized over teaching. But since the calculation of research capacity is done first at the institutional level and consequently internalized by each academic unit, administrators discovered that one way to maximize productivity is to create different roles within each department. While it is true that some sort of role division has always existed in any HEI, on the road to WCU, the university management of emerging HEIs plays an unequivocal role in determining the task for each faculty member. Unlike in many established institutions where faculty self-identification is used to shape the identity of individual faculty members, there is not much room left for faculty autonomy. Furthermore, a research-track faculty is defined as one who could produce a certain number of output. And since under the game

\footnotetext{
${ }^{3}$ In 1995, the Chinese state launched Project 21/1 to give special financial support to the 100 top universities in order to raise their world-class standing in the $21^{\text {st }}$ century. Subsequently, Project 98/5 was announced on the occasion of former President Jiang Zemin's attendance of the centennial anniversary of Peking University in May 1998, to put forth even bolder efforts in state financial investment in the creation of elite universities in China.
} 
plan, research activity is the goal of university's mission, those who cannot contribute to this goal are classified as teaching faculty.

The track system does serve rational purposes. To create a research-intensive, outwardlooking culture from scratch certainly is anything but easy. Constrained by resources and time, university administrators must weigh the cost-benefit of their investment. Personnel assignment is perhaps the single most important investment a university has to make, and a recurrent challenge among faculty distribution of workload. For the sake of efficiency and preventing faculty abuse, the university takes a heavy hand in assigning tracks to faculty member. Relying on the top-down approach rather than self-identification showcases the inherent distrust between the management and the faculty members. More than it should, teaching is regarded as a way out of the competitive research realm. Such a decision creates a de facto hierarchy among faculty members. From management's perspective, this division of labor gives freedom to those who are capable of doing research. But such a process inevitably invites a hierarchy among the faculty members, and leaves the impression that "those who can, do; those who can't, teach."

The tracking of faculty members not only serves the university's desire of achieving WCU and exploits loopholes in the global ranking system, it also created a temporary solution to a dilemma. The fact that there is no easy way to compare the faculty's teaching and research makes it difficult for the university administration to distribute resources and workload. In the tracking system, then, faculty members are only compared within their own track and not across tracks. That is, research faculties are evaluated against one another, but usually not against the teaching faculties. This again makes the divide deeper.

The decisions to assign faculty members to predetermined roles is a compromise to bridge the past and the future. To be clear, HEIs have yet to become like the corporate world where flexible personnel management has been adopted. But HEIs and corporates increasingly bear more similarities. Faculty members are monitored by performance indices: course load, student surveys, number of articles, etc., similar to corporate workers.

This division of roles is certainly not organic but externally enforced. It creates separate streams of faculties inside institutions along lines arbitrarily drawn called "research and teaching." It creates an invisible wall between colleagues as if they are kept apart in two separate worlds. In an atmosphere where research work is prized, the research faculty ultimately enjoys higher status including higher salary and benefits, lower teaching load, leaving teaching faculties marginalized. The most damaging part is perhaps the alienation of faculty from their workplace. When people are assigned to roles, put into a hierarchy of duties, and are told that anyone is disposable and those who are in dissent could easily be forced out, the sense of ownership and commitment to the institution is weakened. The atmosphere becomes more corporate-like rather than academic and congenial. In fact, the relationship among faculty members today is more like "co-workers," but with less comradery. 


\section{Conclusion}

The new structure of globalized universities, as Jamil Salmi wrote in 2009, is not based simply on prestige or self-proclamation. Instead, the proliferation of quantifiable measures offers detailed insights into which universities could make progress. ${ }^{4}$ Therefore, to analyze a workable game plan, with the promise of achieving such status within a limited time window, is essential to understanding how universities grow and change. Perhaps not coincidentally, various game plans all have very similar components such as strengthening the research profile and increasing internationalization. As we have shown in this paper, this is largely due to the fact that research activities can be easily quantified and compared, albeit in problematic ways, while teaching and learning activities cannot. Simon Marginson and Marijk van der Wende expressed very similar points, saying that, "Global comparisons are possible only in relation to one model of institution: that of the comprehensive research-intensive university. This model of HEI is the only one sufficiently widespread throughout the world to lend itself to the formation of a single competition" (2007, p. 308).

The current research-driven, quantified model of creating WCUs coincides with the market orientation, what Luke (2010) calls "edu-business" in higher education development, where economic dimensions of globalization are reshaping the purposes of HEIs and their knowledge production and dissemination. University policy makers and academics are looking outward and performing to external demands in the competitive neoliberal market, more than looking inward at sustaining local values and identities through meaningful educational practices. As we have explored, the difference between use values and exchange values has led tertiary institutions on a pragmatic path to attain status, while paying less attention to the teaching and learning process and the voices of the faculty and student stakeholders that higher education purportedly serves. Through identifying the coexistence of paradoxical forces in the development of WCUs in the global south, this paper aims to lay bare the conceptual complexity in rethinking the landscape of globalizing higher education and highlighting the multiple dimensions, views, and power dynamics within which tertiary institutions and actors are caught. We intend to point out the downsides of the pursuit of WCUs when decision making is over-determined by a small group of stakeholders and a narrow set of indexes, when world-class standing becomes a goal in itself instead of a means to advance knowledge and promote human flourishing. The current approach as identified in this paper is too pragmatically oriented towards quantitative targets, without meaningful debates on the ethical consequences and potential risks to the core values and missions of higher education. Though a difficult proposition, we envision an "in-between" space of fluidity, rather than fixity, to allow the current drive for WCUs in the global south to open up new possibilities and facilitate reciprocal exchanges of multiple perspectives, rather than blindly following the Western metropole and turning the public good of higher education into quantifiable commodities.

\footnotetext{
${ }^{4}$ We argue that status attainment under this new structure still heavily depends on external measures since it "is conferred by the outside world on the basis of international recognition" (Salmi, 2009, p. 4).
} 
New perspectives are emerging if one looks closely. Many university leaders have contributed their insights (see Mohrman, 2005). On a practical ground, John Aubrey Douglass of University of California, Berkeley advocates the idea of "flagship university" (Douglass, 2014). This model differs from WCU that it does not rely on a singular template to guide the development HEI but instead allowing HEIs to carve their own identity around multitude of missions. This idea echoes what, Ruth Simmons, former president of Brown University said before:

There is no formulaic approach to forming a first-class university system... We should think first of the goals of the societies in which they are located and understand that universities are just another way to help societies further these goals (2003, as cited in Mohrman, 2005, p. 229).

Rather than relying on management to decide everything, to build a strong shared governance structure anchored by peer review is the key to sustain the development of HEIs according to Simmons. This point is also shared by Philip Altbach, a renowned higher education scholar:

Excellence in research that is recognized by peers and that pushes back the frontiers of knowledge. (2004, p. 2)

For both, to elevate an institution inevitably means conducting original and creative work that does not necessarily adhere to the rules of the game. After all, the game itself has changed significantly in the past century and there is no reason to believe it won't continue to do so in the future. Both Simmons and Altbach highlight non-quantifiable criteria, such as intellectual excitement, academic freedom, minimal bureaucratic intervention, job security, and the fulfillment of broader social goals as important indicators of "world-class" universities. They hold certain reservations towards the quantified growth of universities calibrated on numbers (whether numbers of publications, citations, or world-class scholars), as in Ruth Simmons' critique of the "assembly line." Efficiency and productivity may get HEIs to a certain level, but it will not attract creative thinkers in large numbers.

Among the four contradictions we discussed in this paper, the role faculty members should take and the kind of knowledge HEIs envision its faculties to produce remains at the center of higher education development. Simmons envisioned that great HEIs should be the vanguard for scholars rather than imposing limits:

Universities promote the capacity of scholars to develop original work that is not immediately applicable or useful... Great universities are not only useful in their own time but in preparing for future times (2003, as cited in Mohrman, 2005, p. 230).

In addition, critical of neoliberal marketization, they urge us to bring back the idea of higher education as ultimately a public good. To our mind, these are the areas where emerging HEIs can contribute to altering the game. The rise of the non-West rest (Zakaria, 2008) means a shift of gravity in higher education from the West being the only dominant center, to a world where literally hundreds of schools of thought contend. But for new HEIs to make such a leap, it is imperative to understand the circumstances that constrained them in this current situation. This particular model where people are emulating has limits. We hope our study contributes in this vein. 


\section{References}

Altbach, P. G. (2004). The Cost and benefits of world-class universities. Academe, 90(1), 1-5.

Altbach, P. G. (1998). Comparative higher education: Knowledge, the university, and development. Norwood, NJ: Ablex.

Baker, D. (2014). The schooled society: The educational transformation of global culture. Stanford, CA: Stanford University Press.

Ball, S. (2003). The teacher's soul and the terrors of performativity. Journal of Education Policy, 18(2), 215-228.

Bosco, J. (2012). The formula as a managerial tool: Audit culture in Hong Kong. Journal of Workplace Rights, 16(3-4), 383-403.

Carey, K. (2015). The end of college: Creating the future of learning and the university of everywhere. New York, NY: Riverhead Books.

Chen, K. H. (2010). Asia as method: Toward de-imperialization. Durham, NC: Duke University Press.

Chen, C. Y. (2015). A study showing research has been valued over teaching in higher education. Journal of the Scholarship of Teaching and Learning, 15(3), 15-32.

Cohen, D. K. (1988). Teaching Practice: Plus que ça change. In P. W. Jackson (Ed.), Contributing to educational change: Perspectives on research and practice (pp. 27-84). Berkeley, CA: McCutchan Publishing Corporation.

Cohen, D. K. (2011). Teaching and Its Predicaments. Cambridge, MA: Harvard University Press.

Cole, J. R. (2009). The great American university: Its rise to preeminence, its indispensable national role, why it must be protected. New York: Public Affairs.

Connell, R. (2007). Southern theory. Crows Nest: Allen \& Unwin.

Dill, D. D., \& Soo, M. (2005). Academic quality, league tables, and public policy: A cross-national analysis of university ranking systems. Higher Education, 49(4), 495-533. doi:10.1007/s10734-0041746-8

Douglass, J. A. (2014). Profiling the flagship university model: An exploratory proposal for changing the paradigm from ranking to relevancy. Retrieved from ERIC databases (ED545195).

Ge, S. (2000). How does Asia mean? (Part I). Inter-Asia Cultural Studies, 1(1), 13-47.

Hayhoe, R. (2001). Lessons from the Chinese academy. In R. Hayhoe, \& J. Pan (Eds.), Knowledge across cultures: A contribution to the dialogue among civilizations (pp. 323-347). Hong Kong: CERC.

Knight, J., \& de Wit, H. (Eds.). (1997). Internationalization of higher education in Asia Pacific countries. Amsterdam: European Association for International Education.

Labaree, D. F. (1997a). How to succeed in school without really learning: The credentials race in American education. New Haven \& London: Yale University Press.

Labaree, D. F. (1997b). Public goods, private goods: The American struggle over educational goals. American Educational Research Journal, 34(1), 39-81.

Li, J. (2012). World-class higher education and the emerging Chinese model of the University. Prospects: Quarterly Review of Comparative Education, 42(3), 319-339.

Luke, A. (2010). Educating the other: Standpoint and theory in the 'Internationalization' of higher education. In E. Unterhalter, \& V. Carpentier (Eds.), Global inequalities and higher education: Whose interests are we serving? (pp. 43-65). New York: Palgrave Macmillan.

Lynch, K. (2015). Control by numbers: New managerialism and ranking in higher education. Critical Studies in Education, 56(2), 190-207.

Marginson, S., \& van der Wende, M. (2007). To rank or to be ranked: The impact of global ranking in higher education. Journal of Studies in International Education, 11(3/4), 306-329. 
Marginson, S., \& Considine, M. (2000). The enterprise university: Power, governance and reinvention in Australia. Oakleigh, Victoria: Cambridge University Press.

Merton, R. K. (1968). The Matthew Effect in science. Science, 159(3810), 56-63.

Mohrman, K., Wanhua, M., \& Baker, D. P. (2008). The research university in transition: The emerging global model. Higher Education Policy, 21(1), 5-27.

Mohrman, K. (2005). Sino-American educational exchanges and the drive to create world- class universities. In C. Li (Ed.), Bridging Minds across the Pacific: U.S.-China Educational Exchanges, 19782003 (pp. 219-235). Lanham, MD: Lexington Books.

Meyer, J. W., Ramirez, F. O., Frank, D. J., \& Schofer, E. (2008). Higher education as an institution. In P. Gumport (Ed.), Sociology of higher education: Contributions and their contexts (pp. 187-221). Baltimore: Johns Hopkins University Press.

Newman, J. H. (1893). The idea of a university, defined and illustrated. London: Longmans, Green \& Co.

Rappleye, J., \& Vickers, E. (2015, November 6). Can Japanese universities really become super global?. Retrieved from http://www.universityworldnews.com/article.php?story $=20151103154757426$

Rhoads, R. A., \& Szelényi, K. ( 2011). Global citizenship and the university: Advancing social life and relations in an interdependent world. Stanford, CA: Stanford University Press.

Rhoads, R. A., Wang, X., Shi, X., \& Yongcai, C. (2014). China's rising research universities: A new era of global ambition. Baltimore: Johns Hopkins University Press.

Salmi, J. (2009). The challenge of establishing world-class universities. Washington, DC: International Bank for Reconstruction and Development \& World Bank.

Schapper, J., \& Mayson, S. (2005). Managerialism, internationalization, Taylorization and the eeskilling of academic work: Evidence from an Australian university. In P. Ninnes, \& M. Hellsten (Eds.), Internationalizing Higher Education: Critical Explorations of Pedagogy and Policy (pp. 181-197). Hong Kong: Springer/Comparative Education Research Center, the University of Hong Kong.

Shin, J. C., \& Toutkoushian, R. K. (2011). The Past, Present, and Future of University Rankings. In C. J. Shin, K. R. Toutkoushian, \& U. Teichler (Eds.), University Rankings: Theoretical Basis, Methodology and Impacts on Global Higher Education (pp. 1-16). Dordrecht: Springer Netherlands.

Simmons, R. (2003, January). How to make a world-Class university. South China Morning Post.

Silver, M. (2015, January 6). If you shouldn't call it the Third World, what should you call it? Retrieved from http://www.npr.org/sections/goatsandsoda/2015/01/04/372684438/if-youshouldnt-call-it-the-third-world-what-should-you-call-it

Stromquist, N. P. (2012). Higher education and the search for excellence in US universities. In B. Adamson, J. Nixon, \& F. Su (Eds.), The reorientation of higher education: Challenging the East-West dichotomy (pp. 165-183). Hong Kong: Springer/Comparative Education Research Center, the University of Hong Kong.

Takayama, K. (2014). Deploying the post-colonial predicaments of researching on/with 'Asia' in education: A standpoint from a rich peripheral country. Discourse: Studies in the Cultural Politics of Education, 37(1), 1-19. doi:10.1080/01596306.2014.927114

Zakaria, F. (2008). The Post-American World. New York \& London: W. W. Norton \& Company.

Zha, Q. (2009). Diversification or homogenization in higher education: A global allomorphism perspective. Higher Education in Europe, 34(3/4), 459-79. 